Article

\title{
Uncertainty of Historic GLAD Forest Data in Temperate Climates and Implications for Forest Change Modelling
}

\author{
Clare Price * and Paul Elsner (iD
}

check for updates

Citation: Price, C.; Elsner, P. Uncertainty of Historic GLAD Forest Data in Temperate Climates and Implications for Forest Change Modelling. ISPRS Int. J. Geo-Inf. 2022, 11, 177. https://doi.org/10.3390/ ijgi11030177

Academic Editor: Wolfgang Kainz

Received: 23 November 2021

Accepted: 2 March 2022

Published: 5 March 2022

Publisher's Note: MDPI stays neutral with regard to jurisdictional claims in published maps and institutional affiliations.

Copyright: (C) 2022 by the authors. Licensee MDPI, Basel, Switzerland. This article is an open access article distributed under the terms and conditions of the Creative Commons Attribution (CC BY) license (https:// creativecommons.org/licenses/by/ $4.0 /)$
Department of Geography, Birkbeck, University of London, London WC1E 7HX, UK; p.elsner@bbk.ac.uk * Correspondence: clare@aridelessordinary.co.uk

\begin{abstract}
Forest loss and degradation are central problems in the context of climate change and biodiversity conservation. The identification of areas of loss relies on accurate base maps. Central datasets in this context are the products of the Global Land Analysis \& Discovery (GLAD) project. Although the GLAD forest cover products are primarily intended to serve as a near real-time flag for areas of forest loss, its historic datasets are increasingly also being used in ways that go beyond this initial focus. To date, very little information is available on the performance of GLAD data in temperate regions. This study aims to address this research gap by comparing the GLAD baseline forest cover maps for the years 2000 and 2010 with UK national forest datasets. The results showed substantial commission errors, which highlight potential problems when deviating from the GLAD datasets' intended use. GLAD data appear to be less useful in regions with a high proportion of medium to low-density canopy cover. In such cases, its application in forest models should only be used in conjunction and cross-calibration with good quality reference data.
\end{abstract}

Keywords: forest data; deforestation modelling; accuracy assessment

\section{Introduction}

Forest loss and degradation have long been recognized as having a negative impact on climate change and biodiversity [1-8]. The identification of these areas of loss relies on accurate base maps [9]. The rising demand for such base maps in areas of the world with poorly mapped forests has led to the increased use of satellite-based global forest datasets to aid in the creation of regional and national forest cover maps $[10,11]$. There is also an increased interest and effort to monitor forest dynamics in the context of carbon accounting, including quantifying degradation within the framework of UN REDD+ [12].

Central datasets in this context are the products of the Global Land Analysis \& Discovery (GLAD) project at the University of Maryland, which has been employed to generate forest cover maps from the year 2000 onwards to quantify deforestation dynamics on a global scale [13]. The GLAD system defines forest cover as minimum $5 \mathrm{~m}$ tall trees with a canopy closure exceeding $30 \%$ of the reference pixel. A forest loss alert is defined as any Landsat pixel that experiences a canopy loss in excess of $50 \%$ cover (https:/ / glad.umd.edu/dataset/glad-forest-alerts, accessed on 16 May 2020).

Studies in Guyana [11] and Gabon [14] have included accuracy results for the GLAD 2000 forest cover base map. Notably, in both research projects, the data had to be recalibrated using canopy cover thresholds that were significantly higher than $30 \%$ before reaching good agreement with local forest reference data. In the case of Guyana, the canopy threshold below which everything is classed as non-forest was $94 \%$ canopy cover, and in the Gabon study, a canopy threshold of $70 \%$ was used to achieve maximum accuracy with the reference data. Therefore, Galiasatos et al. recommend careful calibration with independent datasets before using GLAD data to estimate loss/gain statistics [11].

The apparent tendency for GLAD forest cover data to overestimate tropical forest cover was attributed to classification challenges such as distinguishing between tree plantations 
and old forest, therefore limiting its use in the conservation world [15,16]. However, Tropek also observed that areas with vegetation lower than $5 \mathrm{~m}$ such as soybeans, tea plantations, and pineapple were being classed as forest, indicating a possible thematic link to the areas of commission error [16].

Although the GLAD forest cover products are primarily intended to serve as a near real-time flag for areas of forest loss, it is increasingly also being used in ways that go beyond this initial focus. Examples are the assessment of above-ground biomass across tropical forests [17] and the link between deforestation and malaria incidence [18]. Shah et al. (2018) used Global Forest Cover data to estimate potential locations for the origins of next forest-based emerging infectious disease [19]. Global Forest Cover data have also been used to inform models for bark beetle infestation prediction models [20].

Ceccherini et al. (2020) estimated forest change in the European Union based on a combination of Global Forest Cover data and official forest-area statistics [21]. The paper reported substantial differences in the agreement of Global Forest Watch-derived harvest estimates and respective official national harvest removal data, with the highest correlation coefficients of 0.75 for Portugal and 0.73 for Slovakia and Slovenia. However, a number of other countries such as Belgium, Denmark, Hungary, and the Netherlands showed no or even negative correlations. The reported results and the methodological approach of Ceccherini et al. (2020) were subject to an academic discourse that centred on the general suitability of Global Forest Watch Data for forest harvest models [22-24]. This demonstrates the need for a better and more detailed understanding of GLAD data.

To date, very little information is available on the performance of GLAD data in temperate regions. One example is a study on temperate forests in Japan [25] where the authors noted that GLAD global forest change data should be used with care because of the observed high commission error in locations experiencing small-scale disturbances of $<1$ ha. Rossi et al. (2019) investigated the ability of quantifying harvested sites in a mountainous boreal forest catchment in south-central Norway [26] and found only a moderate quality for detecting harvested sites.

This study aims to address this research gap in order to guide potential users of the data for temperate climates and to frame a better understanding in terms that consider the original design and intended use of the data. In particular, it shall be tested if the tendency of the GLAD forest cover data to overestimate forest cover in tropical environments $[11,14,26,27]$ is also present over forest cover data in temperate environments. Given that GLAD data are available on a global scale, potential users might employ the forest cover data for purposes other than originally intended by the GLAD data creators. Therefore, it is important to develop a better understanding of the uncertainties associated with GLAD data for temperate climate zones. This also includes information about how the uncertainty might vary across regions and different types of non-forest land cover. This can inform potential users about the limits and suitability of GLAD data for studies in temperate climate regions.

This research project compares the baseline forest cover maps from this dataset for the years 2000 and 2010 with UK national forest datasets to investigate their level of accuracy and suitability as a tool for generating such maps. The UK forest data not only fulfil the key requirement that the acquisition method for the reference data should be more accurate than the data being tested [28] (which is more difficult to achieve when both the test and reference data are based on satellite images) but also allows 'pixel by pixel' comparison over the entire area, therefore removing the necessity of sampled data.

\section{Materials and Methods}

The research area for this project covers the island of Britain, i.e., its nations England, Wales, and Scotland. With its geographical location in North-West Europe, its cool and wet winters and warm wet summers, Britain's climate can be classified as temperate maritime. Its choice as a study area was also motivated by the fact that a range of reference datasets are available against which the GLAD data can be tested (see Table 1). 
Table 1. Forest cover datasets used in this research project.

\begin{tabular}{|c|c|c|c|c|c|}
\hline Product \& Data Source & Year & $\begin{array}{l}\text { Smallest Polygon } \\
\text { (MMU) }\end{array}$ & $\begin{array}{l}\text { Acquisition } \\
\text { Method }\end{array}$ & Forest Definition & $\begin{array}{l}\text { Comment/Use of Data } \\
\text { in Study }\end{array}$ \\
\hline $\begin{array}{l}\text { GLAD } 2010 \text { Tree Cover } \\
\text { https://glad.umd.edu/ } \\
\text { Potapov/TCC_2010/, } \\
\text { accessed on 16 May 2020 }\end{array}$ & 2010 & Raster cell area $500 \mathrm{~m}^{2}$ & $\begin{array}{l}\text { Satellite, mainly } \\
\text { Landsat } 7\end{array}$ & $\begin{array}{l}\text { All pixels }>30 \% \\
\text { forest cover }\end{array}$ & Test data \\
\hline $\begin{array}{c}\text { Open Zoomstack } \\
\text { https://www. } \\
\text { ordnancesurvey.co.uk/ } \\
\text { business-government/ } \\
\text { products/open- } \\
\text { zoomstack, accessed on } \\
18 \text { May } 2020\end{array}$ & 2019 & $<10 \mathrm{~m}^{2}$ & $\begin{array}{l}\text { Airborne } \\
\text { imagery and } \\
\text { ground survey }\end{array}$ & $\begin{array}{l}\text { Forest/no forest } \\
\text { polygons }\end{array}$ & $\begin{array}{c}\text { Initial candidate } \\
\text { reference data, } \\
\text { discounted for } \\
\text { temporal difference } \\
\text { with test data but used } \\
\text { to test other reference } \\
\text { sets to aid in choice of } \\
\text { optimum reference set. }\end{array}$ \\
\hline $\begin{array}{l}\text { Corine LC } 2018 \text { https: } \\
\text { / / land.copernicus.eu/ } \\
\text { pan-european/corine- } \\
\text { land-cover/clc2018? } \\
\text { tab=download, accessed } \\
\text { on } 19 \text { May } 2020\end{array}$ & 2018 & $250,000 \mathrm{~m}^{2}$ & $\begin{array}{l}\text { Sentinel-2 } \\
\text { Satellite }\end{array}$ & $\begin{array}{l}\text { All woodland related } \\
\text { LC categories } \\
\text { including agro forest, } \\
\text { broadleaved, } \\
\text { coniferous, mixed } \\
\text { forest, transitional } \\
\text { woodland-shrub }\end{array}$ & $\begin{array}{l}\text { Candidate reference } \\
\text { data-earlier } \\
\text { generations of the data } \\
\text { (2000 and 2012) had } \\
\text { good temporal match } \\
\text { with test data but sets } \\
\text { discounted for } \\
\text { poor resolution. }\end{array}$ \\
\hline $\begin{array}{c}\text { CEH LC } 2000 \\
\text { https:/ / www.jisc.ac.uk/ } \\
\text { geospatial-data\#, } \\
\text { accessed on 2 June 2020 } \\
\text { (no longer running) }\end{array}$ & 2000 & $5000 \mathrm{~m}^{2}$ & $\begin{array}{l}\text { Landsat, IRS } \\
\text { and SPOT } \\
\text { (Landsat } \\
\text { mission } \\
\text { un-specified but } \\
5 \text { assumed) }\end{array}$ & $\begin{array}{l}\text { All woodland-related } \\
\text { LC categories } \\
\text { including } \\
\text { broad-leaved and } \\
\text { coniferous }\end{array}$ & $\begin{array}{l}\text { Candidate reference } \\
\text { data picked because it } \\
\text { was a good temporal } \\
\text { match with GLAD2000 } \\
\text { FC, discounted because } \\
\text { of poor geolocation. }\end{array}$ \\
\hline $\begin{array}{c}\text { CEH LC } 2015 \\
\text { https:/ / www.jisc.ac.uk/ } \\
\text { geospatial-data\#, } \\
\text { accessed on 2 June 2020 } \\
\text { (no longer running) }\end{array}$ & 2015 & $5000 \mathrm{~m}^{2}$ & $\begin{array}{l}\text { Landsat } \\
\text { 8/AWIFS }\end{array}$ & $\begin{array}{l}\text { All woodland-related } \\
\text { LC categories } \\
\text { including } \\
\text { broad-leaved and } \\
\text { coniferous }\end{array}$ & $\begin{array}{l}\text { Candidate reference } \\
\text { data picked because a } \\
\text { reasonable temporal } \\
\text { match with GLAD } 2010 \\
\text { FC, superseded by } \\
\text { discovery of NFI10, LC } \\
\text { used in habitat analysis. }\end{array}$ \\
\hline $\begin{array}{c}\text { National Forest } \\
\text { Inventory https:/ / data- } \\
\text { forestry.opendata.arcgis. } \\
\text { com/search?tags=GB, } \\
\text { accessed on } 26 \\
\text { August } 2020\end{array}$ & 2010 & $5000 \mathrm{~m}^{2}$ & $\begin{array}{c}\text { Airborne } \\
\text { imagery and } \\
\text { ground survey }\end{array}$ & $\begin{array}{l}\text { All woodland-related } \\
\text { categories with } \\
\text { canopy cover }<30 \% \\
\text { removed including } \\
\text { 'non-woodland' and } \\
\text { 'assumed woodland' }\end{array}$ & $\begin{array}{l}\text { Identified as optimum } \\
\text { data to test GLAD } 2010 \\
\text { and } 2000 \text { FC. }\end{array}$ \\
\hline $\begin{array}{l}\text { National Forest } \\
\text { Inventory https:/ / data- } \\
\text { forestry.opendata.arcgis. } \\
\text { com/search?tags=GB, } \\
\text { accessed on } 26 \\
\text { August } 2020\end{array}$ & 2018 & $5000 \mathrm{~m}^{2}$ & $\begin{array}{c}\text { Airborne } \\
\text { imagery and } \\
\text { ground survey }\end{array}$ & $\begin{array}{l}\text { All woodland-related } \\
\text { categories with } \\
\text { canopy cover }<30 \% \\
\text { removed including } \\
\text { 'non-woodland, } \\
\text { felled, failed, } \\
\text { assumed, } \\
\text { ground-prep, shrub, } \\
\text { uncertain and } \\
\text { wind-blow' }\end{array}$ & $\begin{array}{l}\text { Similar in most aspects } \\
\text { to the OS2019 so used } \\
\text { as a 'control' for the } \\
\text { NFI dataset, i.e., low } \\
\text { accuracy between } \\
\text { NFI2018 and OS } 2019 \\
\text { would have reduced } \\
\text { the credibility of the } \\
\text { NFI } 2010 \text { dataset. }\end{array}$ \\
\hline
\end{tabular}

Oloffson [29] details several key areas to consider when undertaking an accuracy assessment, including the spatial unit, the labelling protocol, and defining the terms of agreement, all of which have formed part of the data preparation for this study. Other aspects considered here include checking the pre and post re-projection areas for any discrepancy. 
The GLAD FC data are produced by the University of Maryland and are freely available for download via the GLAD (https:/ / glad.umd.edu/Potapov/TCC_2010, accessed on 15 May 2020) website. Although the focus of the GLAD laboratory is on identifying areas of forest loss in near real time as well as decadal forest gain [13], this research focuses on the positional and thematic accuracy of the forest cover datasets for the years 2010 and 2000, upon which the forest loss and gain maps are built. Although it was originally intended that the baseline forest cover maps should be updated every 10 years, the forest cover map for 2020 was not available; therefore, it was only possible to test GLAD forest cover maps for 2000 and 2010. The data are based on the interpretation of multispectral satellite imagery, predominantly from the Landsat 7 satellite at a spatial resolution of $30 \mathrm{~m} \times 30 \mathrm{~m}$ (at the equator) and consist of a set of pixels each with an attribute representing the percentage of tree canopy cover. The data were re-projected to EPSG 2770 (British National Grid), and a comparison was made with canopy areas obtained from a report generated from the Global Forest Watch website to confirm that the process of re-projecting the data had not affected the grid cell areas. The resulting difference between the report and the uploaded data is less than $1 \%$, which was deemed to be an acceptable level of uncertainty.

To ascertain the best reference dataset, four reference sets were considered as possible candidates (in order of consideration); OS Open Zoomstack (OS) followed by the Corine LC data, the Centre for Ecology and Hydrology (CEH) LC, and lastly the National Forest Inventory (NFI) data. The inclusion of 4 different sets was not foreseen at the study outset but was a consequence of attempting to improve either the temporal difference, method of acquisition, or resolution (MMU) of the optimum dataset. Although the OS data were initially considered as the ideal reference set due to its high resolution and superior method of acquisition and ground-truthing, due to the lack of availability of pre- 2019 data, it was subsequently only used to test the other candidate reference sets to quantify the differences and further aid the choice of an optimum set.

The pre-analysis data preparation methods involved downloading vector files covering England for each dataset. Then, polygons belonging to categories that best represented the GLAD forest definition (30\% canopy cover) were aggregated and rasterized into forest/no forest grid cells using the same grid dimensions as the GLAD FC data to enable the creation of accuracy grids.

A description of each candidate dataset follows in the order that the analysis was carried out, with a brief explanation of its respective pros and cons, which is further expanded in Sections 2.1 and 2.2.

The OS data produced by the Ordnance Survey constitute a geospatial database containing over 400 million human-made and natural landscape features across the UK (including forests) that is constantly updated using a combination of GPS technology and aerial photography (https:/ / www.ordnancesurvey.co.uk/about/history, accessed on 17 July 2020). The minimum mapping unit (MMU) is less than $10 \mathrm{~m}^{2}$ with widths of less than $10 \mathrm{~m}$ and the data are in a forest/no forest format, so aggregation of categories was not necessary. Due to its acquisition method being different from and higher resolution than the test data, the OS data was initially seen as the optimum set, but because digital data were only available for the current year (2019) resulting in a time gap of 9 and 19 years with the test data, it was discounted as a suitable reference set.

Corine LC is a pan-European product that includes data from the Sentinel-2 satellite run by the European Space Agency and was the second dataset to be considered. The data have an MMU of 250,000 $\mathrm{m}^{2}$ and are classified into 43 different land cover classes. It was discounted because of its large MMU of $250,000 \mathrm{~m}^{2}$.

The CEH data are a parcel-based land cover classification that divides satellite images into 21 Broad Habitats as defined by the Joint Nature Conservation Committee, which encompass all UK habitats [30]. Two datasets were available for the years 2000 and 2015. The CEH2000 dataset, which was a good temporal match with GLAD 2000 FC, was found to have significant geolocation problems and discounted. The incorporation 
of OS geolocation data into the CEH2015 LC solved the geolocation problems, and this dataset was subsequently used in our commission error habitat analysis.

NFI data were the fourth and final dataset to be included. It represents a rolling programme of the Forestry Commission (FC), which is Great Britain's principal organisation for forestry and tree-related research. This dataset combined the geolocation accuracy of the OS dataset for its forest boundaries with additional advantages of airborne acquisition and extensive ground surveys for validation. These ground surveys provide a randomly selected and representative sample of approximately 10,000 one hectare plots across Britain. In a second step, a Quality Assurance team undertook visual checks of $100 \%$ of the ground sample assessments and additionally reassessed a minimum of $5 \%$ of sample sites (https:/ / www.forestresearch.gov.uk/tools-and-resources/national-forest-inventory/ about-the-nfi /, accessed on 10 July 2020). Therefore, the authors of this paper are confident that the NFI data had been rigorously tested and validated and could serve as a reference dataset for our analysis of GLAD data accuracy.

The NFI data are available yearly from 2010 to the present. It includes both urban and rural woods larger than $5000 \mathrm{~m}^{2}$ with a canopy cover of $20 \%$ and contains attributes such as tree type and land use as additional information. Its major advantage over the OS data is that yearly datasets are freely available back to the year 2010 .

Whilst temporal and resolution differences are abundantly clear between the sets, the selection and aggregation of different forest categories that best represented the GLAD forest cover definition (i.e., any vegetation above $5 \mathrm{~m}$ with a canopy cover of around $30 \%$ ) were recognized as being an equally important metric in the choice of reference set. Whilst the OS2019 dataset was based on a simple forest/no forest format, the Land Cover and forest inventory reference sets contained several categories, and the decision to include or exclude the data was based on the category name, so in the case of the LC datasets, this included all categories associated with woodland LC such as 'broadleaf', 'conifer', and 'mixed woods', and for the NFI, it excluded categories such as 'windblow' and 'felled'. Although the inclusion of ambiguous categories (such as 'transitional woodland shrub' or 'uncertain and windblow') inevitably leads to the possibility of including areas that are less than $30 \%$ canopy cover, these categories were found to be an insignificant proportion of the datasets. The choice of attributes making up the forest data in the candidate reference datasets is outlined in Table 1.

The logic used to generate accuracy grids for determining a suitable reference dataset as well as determining the accuracy of the GLAD FC for 2000 and 2010 can be defined in the simplest terms due to the binary forest/no forest structure of the data. Each dataset contains either 'forest' or 'no forest' pixels, and combining the sets generates 4 outcomes (Table 2).

Table 2. Reference data vs. test data logic.

\begin{tabular}{cccccc}
\hline Reference & Value & Test Data & Value & Sum & Result \\
\hline Forest & 1 & Forest & 200 & $1+200=201$ & True Positive \\
\hline Forest & 1 & No Forest & 0 & $1+0=1$ & False Negative \\
\hline No Forest & 0 & Forest & 200 & $0+200=200$ & False Positive \\
\hline No Forest & 0 & No Forest & 0 & $0+0=0$ & True Negative \\
\hline
\end{tabular}

The results are defined in terms of their commission and omission error [28] as set out below:

Commission error $=1-($ True Positive $/($ True Positive + False Positive $)$ ) and is a ratio of the total area of test data relative to the incorrectly placed test data. It is the inverse of the Positive Predictive Value (PPV), which is also known as the Users accuracy.

Omission error $=1-($ True Positive/(True Positive + False Negative) $)$ and is the ratio of the total area of reference data relative to the incorrectly placed test data. It is the inverse of the TPR or True Positive Rate and known as the Producers accuracy. 
To create an inter-map agreement matrix, the reference and test data grids were combined to produce a summed grid containing pixel counts for each of the four outcomes (True Positive, True Negative, False Positive, and False Positive). The pixel counts were multiplied by the pixel size to calculate the areas of commission and omission errors. The grids were visually inspected for spatial patterns. This method was performed between candidate reference datasets as a way of determining the optimum reference dataset as well as to assess the accuracy of the GLAD FC data.

The commission error grids from the accuracy assessments were combined with 2015 CEH habitat data. The resultant habitat-classed commission error grid was combined with the GLAD FC percentage canopy cover, as summarised in Figure 1.

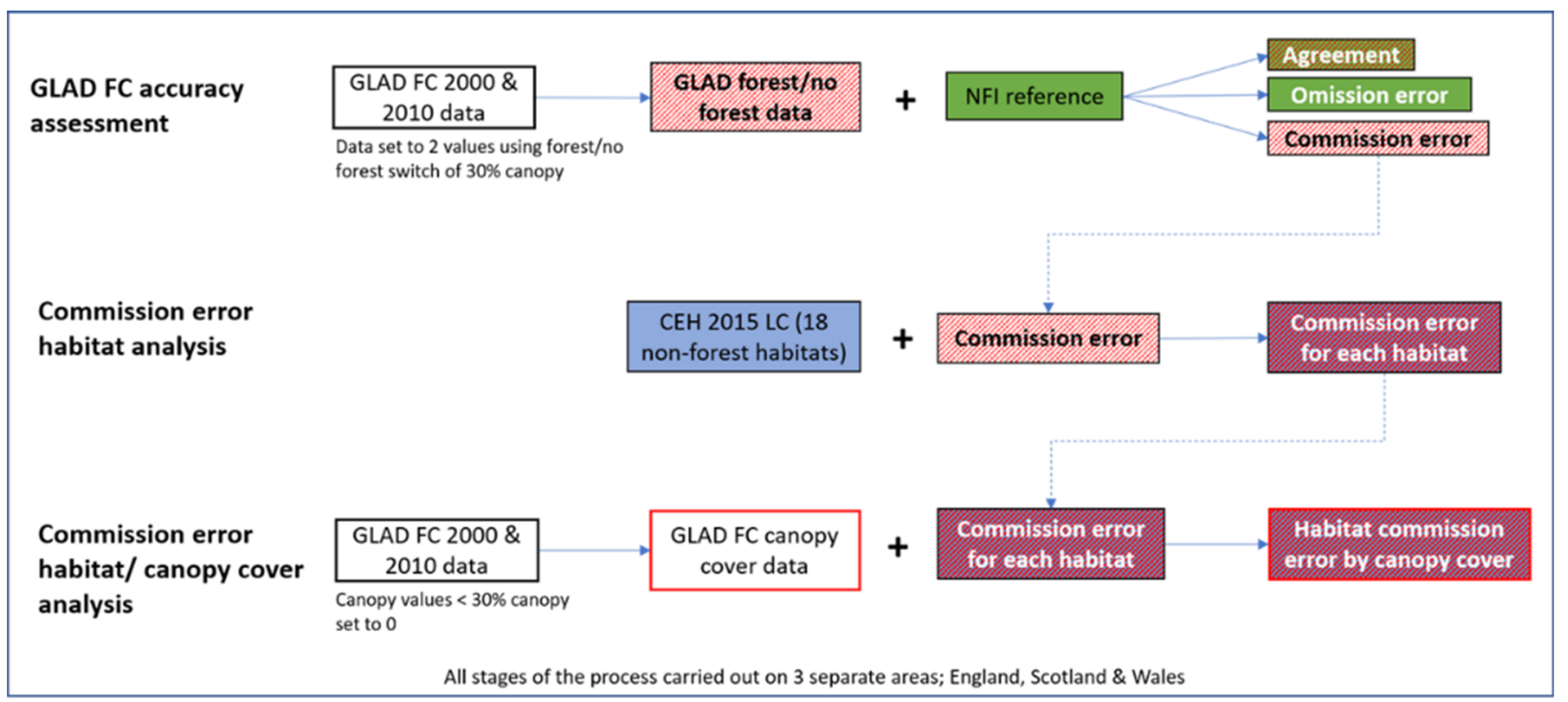

Figure 1. Flow chart showing steps involved in the creation of the accuracy assessments and commission analysis.

\subsection{Reference Data Analysis Results and Discussion}

As mentioned earlier in the section, to choose the optimum reference dataset, the Ordnance Survey (OS) data were compared to the Corine Land Cover and the Centre for Ecology and Hydrology (CEH) Land Cover as well as the National Forest Inventory data (Table 3).

Table 3. Accuracy results comparing OS with CEH, NFI, and Corine data.

\begin{tabular}{|c|c|c|c|}
\hline Reference vs. Test & Time Diff & Commission Error & Omission Error \\
\hline \multicolumn{4}{|c|}{ Reference data accuracy assessment } \\
\hline OS 2019 vs. Corine forest 2018 & 1 & 0.216 & 0.496 \\
\hline OS 2019 vs. CEH forest 2015 & 4 & 0.205 & 0.217 \\
\hline OS 2019 vs. CEH forest 2000 & 19 & 0.463 & 0.421 \\
\hline OS 2019 vs. NFI 2018 & 1 & 0.133 & 0.198 \\
\hline OS 2019 vs. NFI 2010 & 9 & 0.137 & 0.162 \\
\hline \multicolumn{4}{|c|}{ Further assessments to aid choice of ref for GLAD 2000} \\
\hline CEH 2000 vs. GLAD FC 2000 & 0 & 0.47 & 0.42 \\
\hline NFI 10 vs. GLAD FC 2000 & 10 & 0.39 & 0.26 \\
\hline
\end{tabular}


A visual inspection of the resultant grids reveals some of the more obvious causes of the errors, which can be categorized by differences in minimum mapping unit (MMU), positional inaccuracies, and temporal issues.

The OS $2019 \mathrm{MMU}$ is $<10 \mathrm{~m}^{2}$, which is considerably smaller than the Corine and CEH MMU of $250,000 \mathrm{~m}^{2}$ and $5000 \mathrm{~m}^{2}$, respectively. This difference causes an omission error of nearly 50\% when the OS 2019 data are compared to the Corine 2018 and illustrates the potential for large inaccuracies when using low-resolution land cover datasets in areas with small land parcel size. Figure 2 compares the two datasets over a small area in the north of England, with the Google Earth image further demonstrating the small parcel size of woods captured in the OS 2019 data that are absent in Corine 2018 (A).
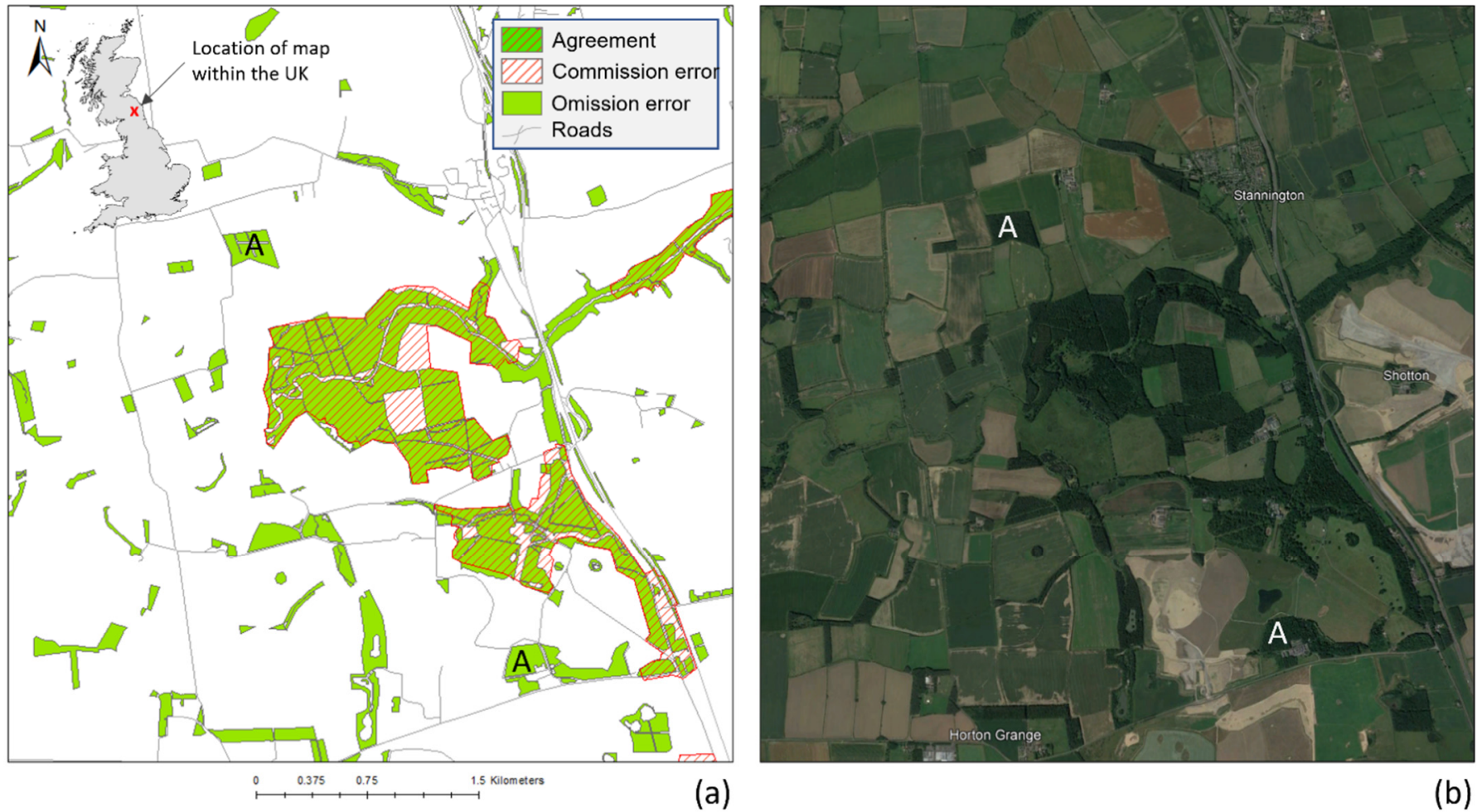

(a)

Figure 2. (a) OS 2019 forest (reference in green) vs. 2018 Corine (test in red stripe), (b) Google Earth imagery date 17 July 2021.

The lowest errors were calculated between the OS and NFI data partly due to its shared positional data and, in the case of the 2018 NFI data, its temporal similarity. The lack of significant difference between the OS 2019 versus NFI 2018 and NFI 2010 result (the latter with an 8-year gap in the datasets) is an indication that the amount of forest change over this period is low. This is a trend seen in the NFI data over a longer period of 15 years with an overall increase in forest cover of 4\% from 2000 to 2015 corroborated by the 2015 NFI report [31].

A significant proportion of the areas of omission in the OS 2019 vs. NFI 2018 grids are located in plantations (or tree farms) and are likely due to the OS being less rigorous with its monitoring of these fast-changing intra-forest areas, which explains the slight increase in omission errors in 2018 NFI data compared to the 2010 NFI results. The NFI data contain attributes detailing felled areas within plantations, as a central part of its remit is to monitor these areas.

\subsection{Choice of Optimum Reference Dataset}

Based on the initial analysis described above, the NFI 2010 data were chosen as the optimum reference dataset for both the GLAD FC 2010 and 2000 data. For the 2010 
FC, a direct temporal agreement is present. Although there is a temporal difference of 10 years between GLAD FC 2000 and this reference dataset, the coarse data resolution of the 2000 Corine data immediately precludes its use a reference dataset, the $2000 \mathrm{CEH}$ data are beset with positional and thematic errors, and the 2000 NFI data are not available in a digital format.

This time difference is potentially problematic because observed differences might be caused by genuine changes in forest cover. However, the areal difference between the NFI datasets report a $1 \%$ increase in forested area over this 10 -year period, which is in stark contrast to the GLAD FC, which calculates a 30\% increase. The low level of change calculated by the NFI data is corroborated by Bibby [32], whose report on land change in the UK from 1983 to 2008 states that the largest change in land use over this period was from agriculture to forestry and woodland, initially at a rate of $1 \%$ increase a year, slowing to $0.24 \%$ post 2000 .

Therefore, the assumption was that the areal extent of forest cover over this period remained relatively stable, with minor amounts of loss and gain by way of tree harvesting and grant-assisted broadleaf wood regeneration.

\section{Results}

\subsection{GLAD FC 2010 and 2000 Accuracy Assessment}

Having identified the 2010 NFI as the most suitable reference dataset for both GLAD FC datasets, a series of accuracy grids were generated for England, Wales, and Scotland. A summary of the results is presented in Table 4.

Table 4. Accuracy results of GLAD FC 2000 and 2010.

\begin{tabular}{|c|c|c|c|c|c|}
\hline England & Area $\mathbf{k m}^{2}$ & Wales & Area $\mathrm{km}^{2}$ & Scotland & Area $\mathbf{k m}^{2}$ \\
\hline \multicolumn{6}{|c|}{ GLAD FC 2010} \\
\hline NFI 10 & $12,570.49$ & NFI 10 & 3083.98 & NFI 10 & $14,140.25$ \\
\hline GLAD $2010>30$ & $20,357.60$ & GLAD $2010>30$ & 5033.47 & GLAD $2010>30$ & $20,885.17$ \\
\hline True positive & 9844.49 & True positive & 2377.45 & True positive & $10,690.67$ \\
\hline False negative & 3332.43 & False negative & 706.53 & False negative & 3449.58 \\
\hline False positive & $10,513.12$ & False positive & 2656.01 & False positive & $10,194.50$ \\
\hline True negative & $106,704.97$ & True negative & $14,995.00$ & True negative & $54,440.25$ \\
\hline Commission error $(\%)$ & 51.6 & Commission error $(\%)$ & 52.8 & Commission error $(\%)$ & 48.8 \\
\hline Omission error (\%) & 25.3 & Omission error (\%) & 22.9 & Omission error (\%) & 24.4 \\
\hline \multicolumn{6}{|c|}{ GLAD FC 2000} \\
\hline NFI 10 & $12,570.49$ & NFI 10 & 3083.98 & NFI 10 & $14,140.25$ \\
\hline GLAD $2000>30$ & $15,181.63$ & GLAD $2000>30$ & 3866.06 & GLAD $2000>30$ & $15,884.75$ \\
\hline True positive & 9269.93 & True positive & 2277.00 & True positive & 9967.00 \\
\hline False negative & 3300.56 & False negative & 806.98 & False negative & 4173.25 \\
\hline False positive & 5911.71 & False positive & 1589.06 & False positive & 5917.75 \\
\hline True negative & $111,912.80$ & True negative & $16,061.96$ & True negative & $58,717.00$ \\
\hline Commission error $(\%)$ & 38.9 & Commission error $(\%)$ & 41.1 & Commission error $(\%)$ & 37.3 \\
\hline Omission error (\%) & 26.3 & Omission error (\%) & 26.2 & Omission error (\%) & 29.5 \\
\hline
\end{tabular}

The most notable results are the high commission errors particularly regarding 2010 NFI vs. 2010 GLAD FC with commission errors of around 50\%. This indicates that $50 \%$ of the 2010 GLAD FC data is not flagged as "Forest" in the reference dataset. It is also notable that the GLAD 2000 data compared to the NFI 2010 has a smaller commission error (a decrease of around 10\%) despite a 10-year time gap. 
A visual inspection of both accuracy maps highlights this $10 \%$ difference in commission error and also illustrates that the spatial distribution of the commission errors is predominantly situated in areas that are isolated from the reference forest and are likely to be thematic errors rather than problems with geolocation (Figure 3a,b).

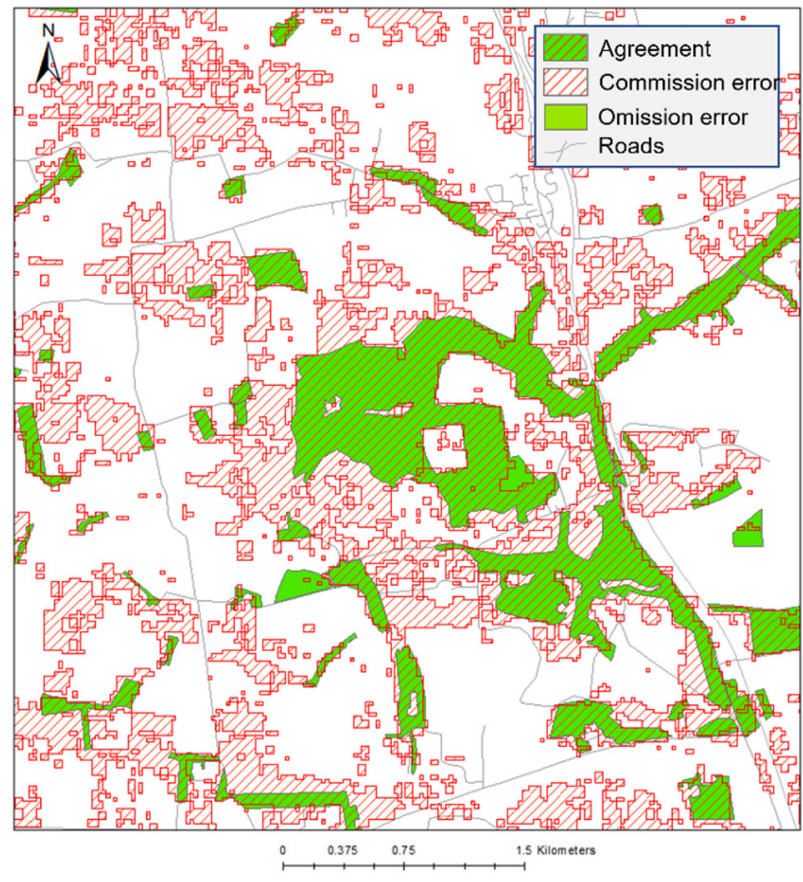

(a)

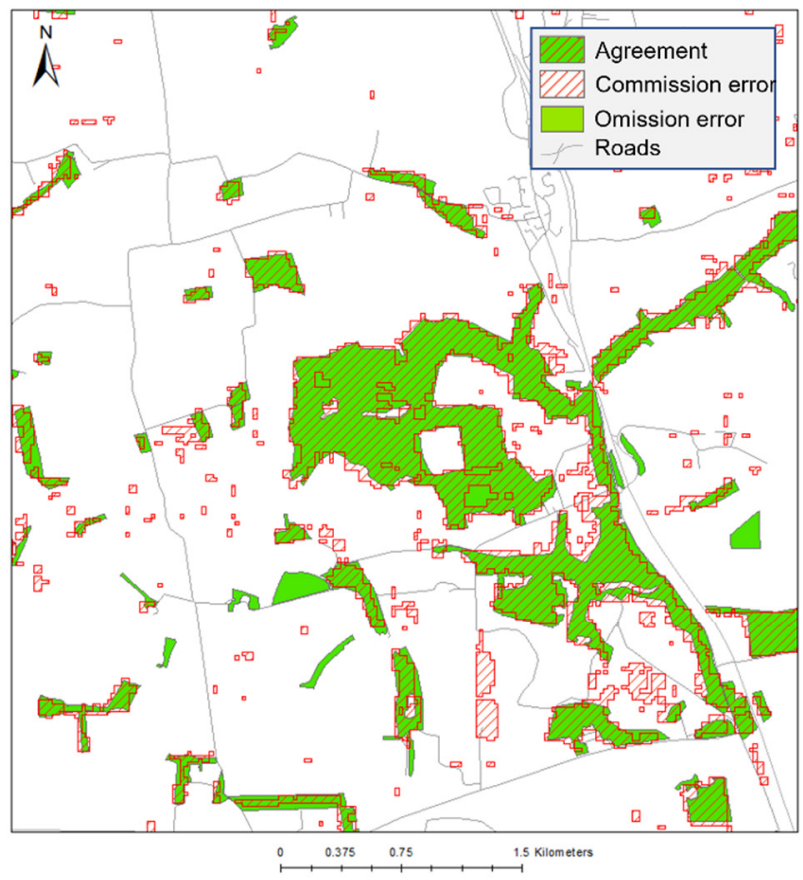

(b)

Figure 3. Accuracy maps for (a) 2010 NFI (reference in green) vs. 2010 GLAD FC, (b) 2010 NFI vs. 2000 GLAD FC. (location within the UK the same as Figure 2).

\subsection{Commission Error Habitat Analysis for GLAD FC Forest Data}

To analyse the thematic errors associated with the high commission errors calculated for both GLAD FC maps, these errors were combined with the CEH 2015 Land Cover dataset, which comprises 20 habitats covering the whole of the UK, including heathland habitats such as heather, heather grassland, bog, and inland rock. The results of this analysis are summarized in Figure 4.

It can be seen that in England and Wales, the habitat classification with the highest commission error is the land cover class Improved grassland (pasture), whilst in Scotland, the Heather land cover class has the highest error. Approximately $70 \%$ of that land cover class was falsely labelled as "Forest" in the GLAD 2010 data. This illustrates that classification errors were not only confined to heathland habitats but, overall, were more prevalent in improved grassland habitats.

These trends were observed for both the GLAD 2000 and 2010 commission errors. However, there were subtle differences: the GLAD 2000 commission errors were distributed over more heathland habitats and less improved grassland compared to the GLAD 2010 errors (Figure 4). As mentioned in the accuracy assessment results, the 2000 FC data have a smaller commission error than the 2010 data, and this indicates that the increase in error is predominantly in areas of improved grassland.

Further calculation of the national proportions of each habitat for England, Wales, and Scotland revealed that 'grassland' and 'arable' constituted the largest habitats for England and Wales, whilst in Scotland, the 'mountain, heath and bog' habitats dominated. To account for this, the respective commission errors were compared to the national habitat proportion. 


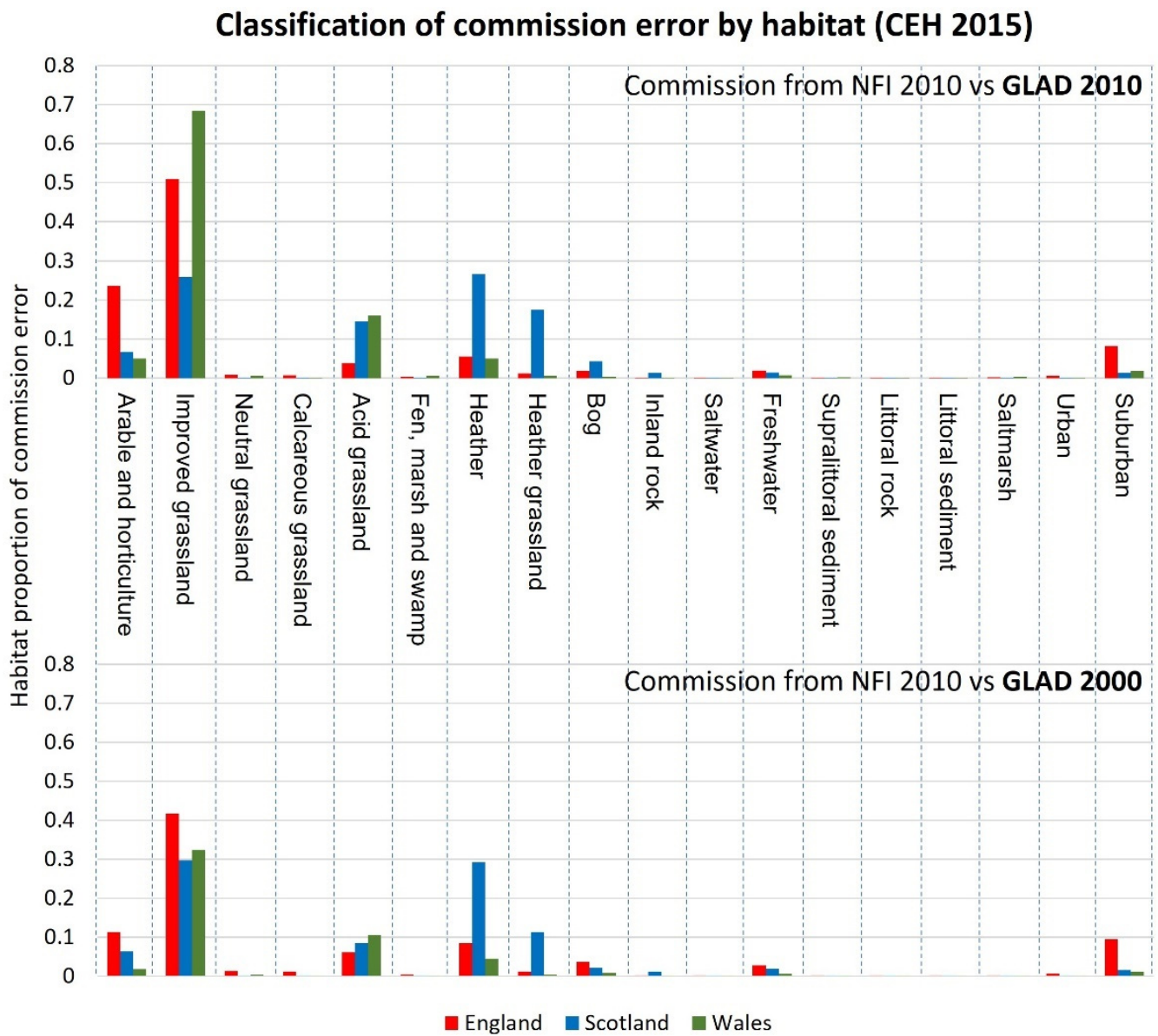

Figure 4. Classification of commission error by habitat for 2010 NFI vs. 2010 GLAD FC and 2010 NFI vs. 2000 FC.

This normalisation cancelled out the high values for improved grassland, which dominate the commission errors and results in the proportion of commission error areas for the Heather habitat being consistently higher than the national proportion for these habitats. This was observed in all three nations and on both GLAD 2000 and 2010 datasets and indicated that proportional to the national habitat, the commission error was most prevalent for the heather.

The results also showed that whilst the heather habitat values were consistently higher than other habitats, within the heather values, there were differences between the nations and across the two GLAD datasets. England has the highest values for both GLAD 2000 and 2010 data, whereas Scotland has the lowest value for the 2000 GLAD FC data and Wales has the lowest value in the 2010 GLAD FC data (Figure 5). These differences are likely to be partly attributed to the large temporal difference between the GLAD 2000 FC and the habitat data.

Figure 5 also illustrates that the land cover classes Fen, marsh, and swamp category shows similarly high values across all three nations, as do the fresh water and littoral rock values for England. However, these habitats form less than $0.7 \%$ of the national habitat.

On the nations level, the areas of heather misclassified as forest for England and Wales constitute $5 \%$ and $6 \%$, respectively, of the commission error. In Scotland, which has a much higher national percentage of heather, the commission error rises to $29 \%$. This translates into a reduction in 2010 GLAD forest cover for England and Wales by 3\% and 2\%, respectively, whilst in Scotland, it reduces the forest cover by $14 \%$, with smaller reductions for the 2000 GLAD forest cover. 


\section{Commission error habitat compared to National habitat}

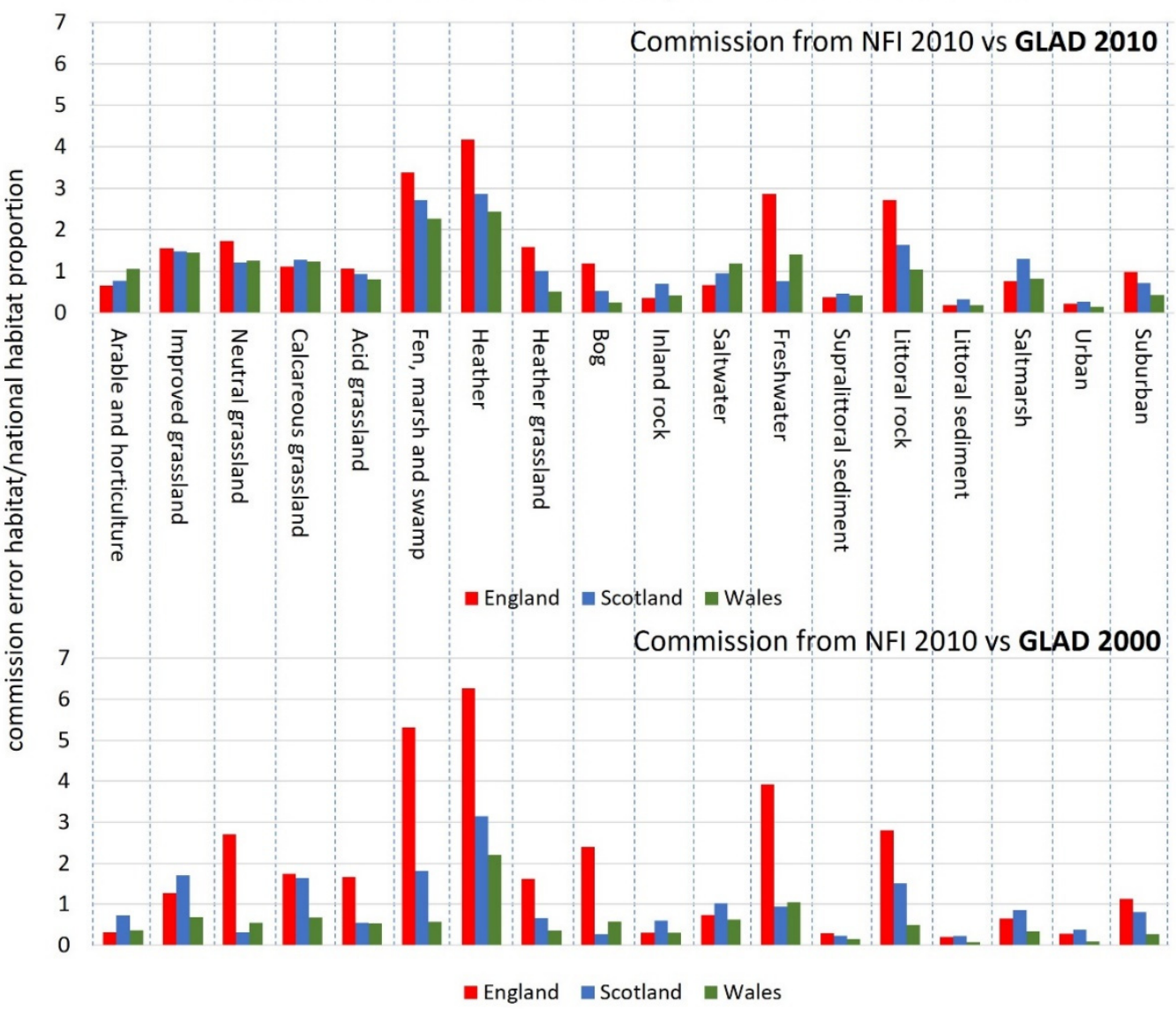

Figure 5. Difference between national habitat and commission error habitat GLAD FC 2010 and GLAD FC 2000 (positive numbers indicate commission error habitat proportion larger than national habitat proportion).

\subsection{Relationship between GLAD FC Percentage Canopy Cover and Commission Errors}

Research in the context of tropical environments showed the level of canopy cover that is used as the threshold for GLAD forest data can have a substantial effect on the accuracy $[11,13]$. This study tested if this was also the case for temperate environments. This was completed by graphically illustrating the area of canopy cover for the full range of percentage canopy cover. Figure 6 illustrates that for the 2010 GLAD FC, there was only a small area of the UK with canopy cover above $90 \%$. More than $70 \%$ of the forested area had canopy cover between 30 and $85 \%$. These results were consistent across the three nations. The distribution of canopy cover over the 2000 GLAD FC showed substantially less area with canopy covers below approximately $40 \%$ and an increase in areas with canopy cover over $90 \%$.

The results of combining the agreement and commission grids from the NFI accuracy assessment with the GLAD FC percentage canopy cover grids showed the same trends as the complete data, i.e., a smaller proportion of the 2000 data having areas below $40 \%$ canopy cover than the 2010 data. The 2010 commission areas show a gradual decrease in canopy cover with increasing canopy covers (until 90\%), whereas the 2000 commission areas only show this decline with increasing canopy cover in the English data. In Scotland and Wales, the commission area remains constant across a range of canopy covers from 40 to $100 \%$ (Figure 7). This corresponds to a reciprocal increase in the agreement areas. 

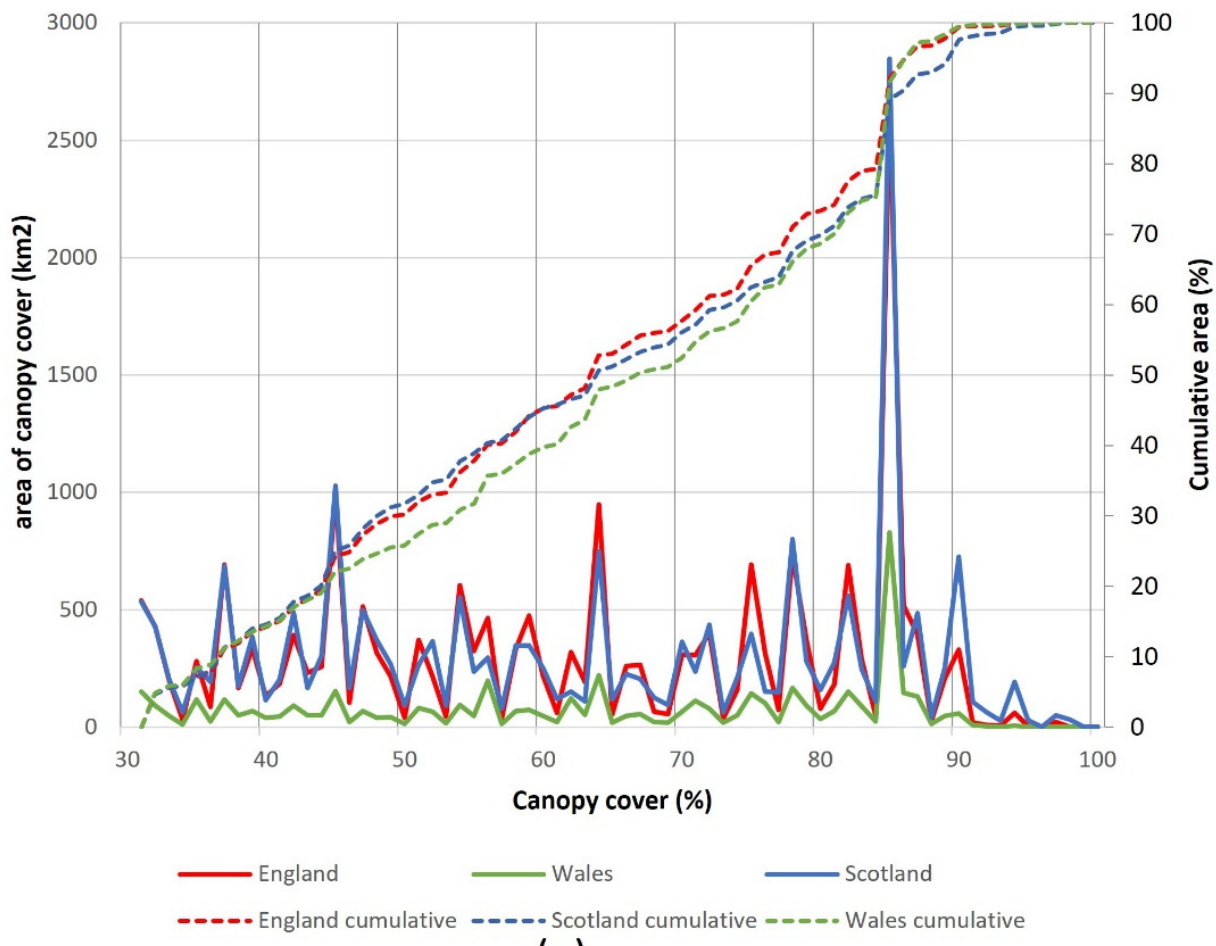

(a)

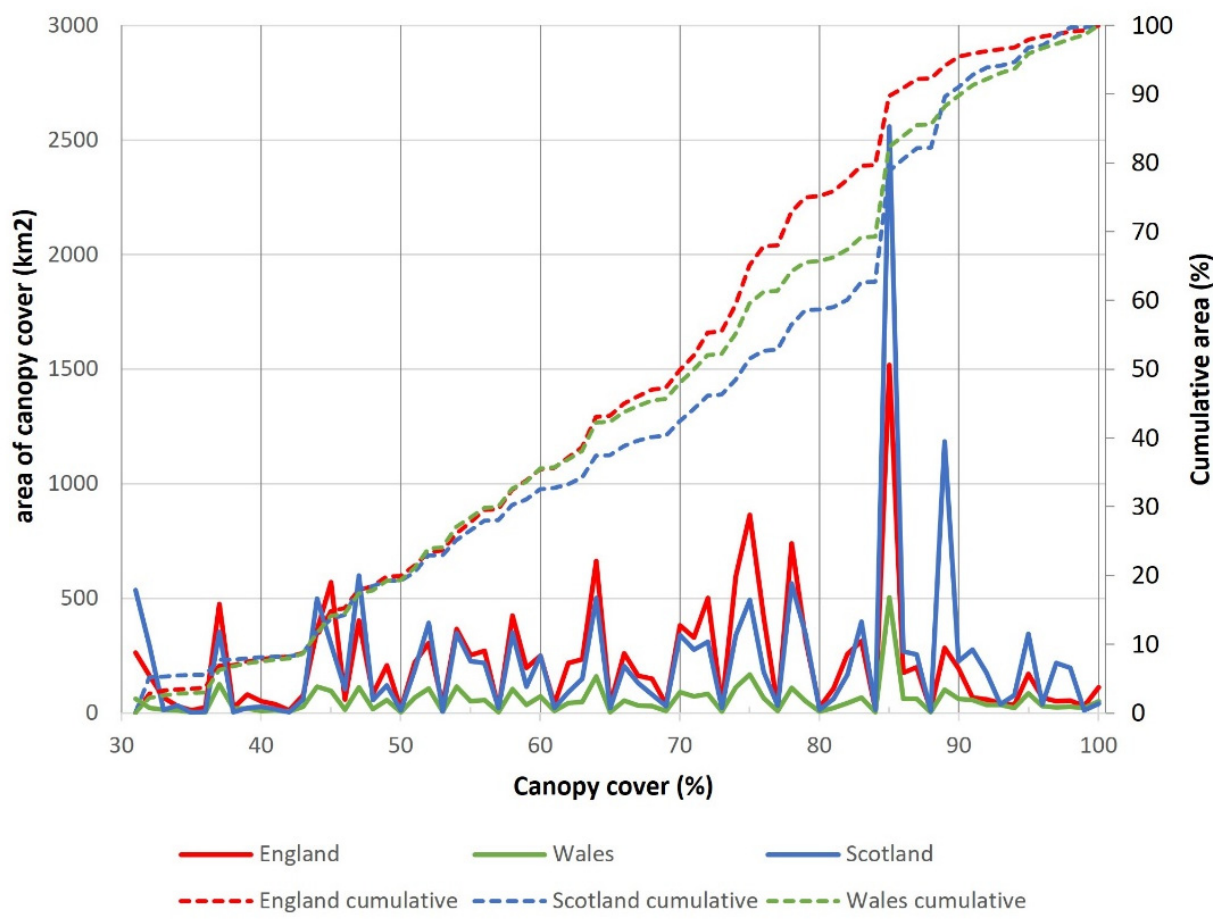

(b)

Figure 6. GLAD FC > 30\% canopy cover vs. area of cover for (a) 2010 and (b) 2000. 


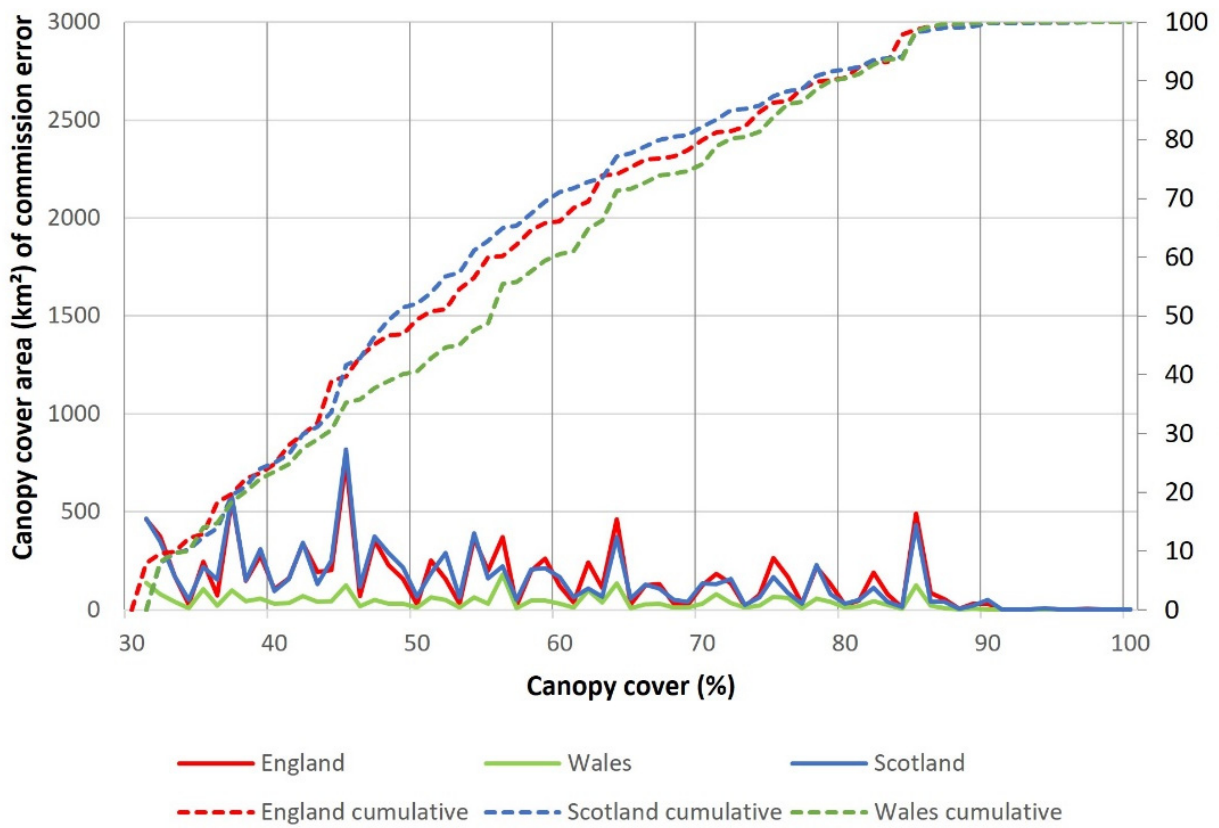

(a)

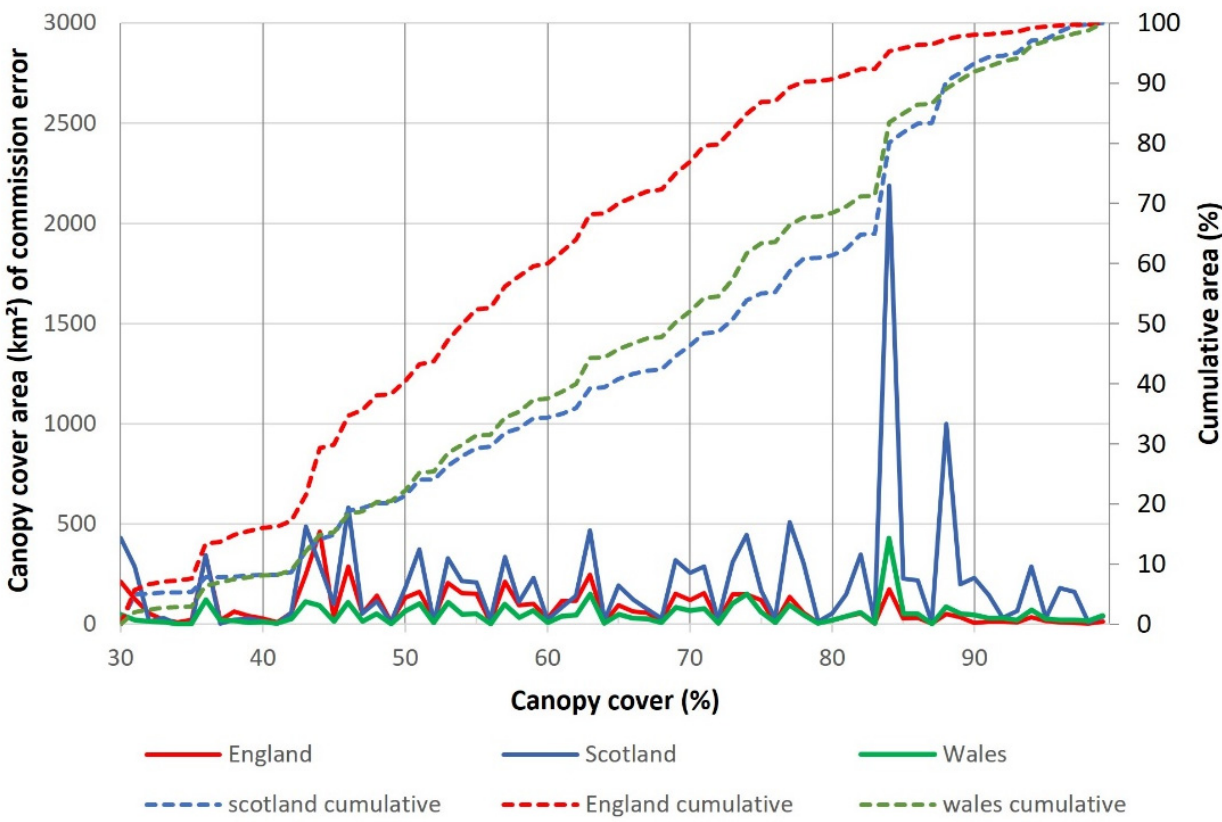

(b)

Figure 7. Areas of commission error between NFI and GLAD FC against percentage of canopy cover for (a) 2010 and (b) 2000.

The results of combining the habitat commission error data with the canopy values show that the Improved grass habitat (which is the habitat with the highest proportion of commission error) is relatively evenly distributed across the canopy values in contrast to the Heather habitat that shows an overall decrease with an increase in canopy cover, particularly in the 2010 dataset (Figure 8). 


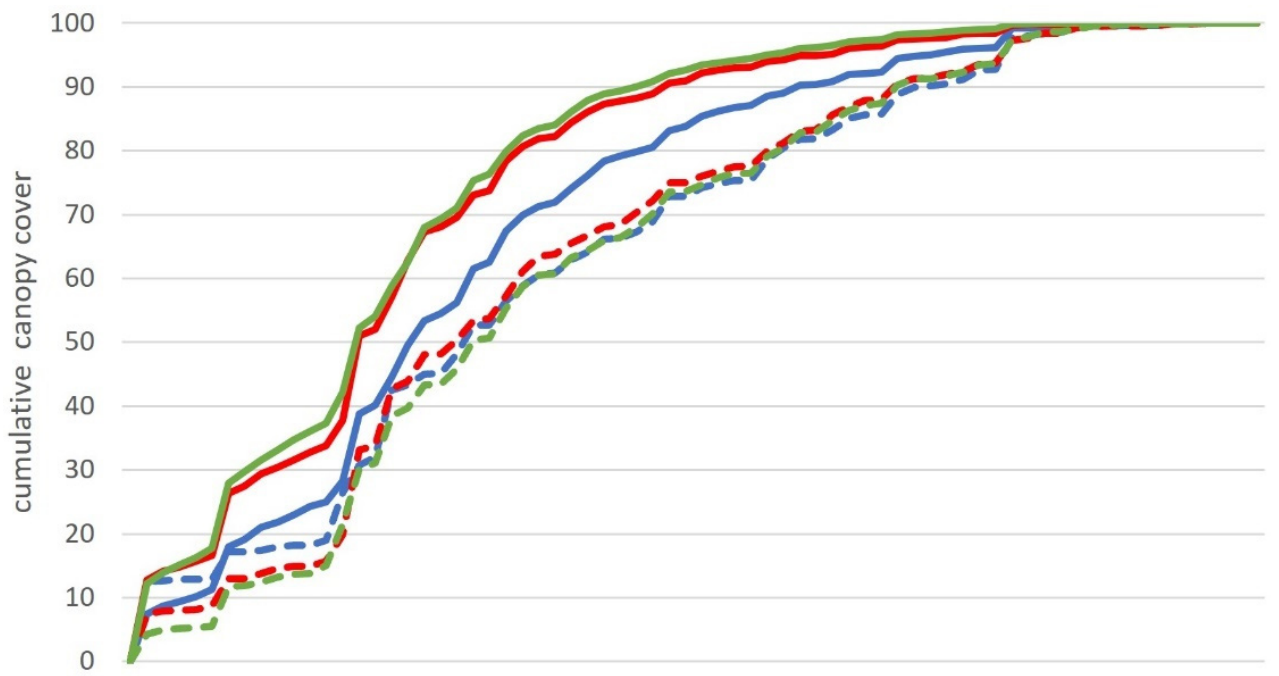

$\begin{array}{llllllllllllllllllllllll}31 & 34 & 37 & 40 & 43 & 46 & 49 & 52 & 55 & 58 & 61 & 64 & 67 & 70 & 73 & 76 & 79 & 82 & 85 & 88 & 91 & 94 & 97 & 100\end{array}$ $\%$ canopy cover

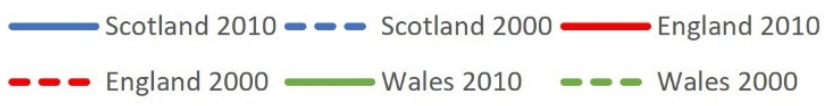

(a)

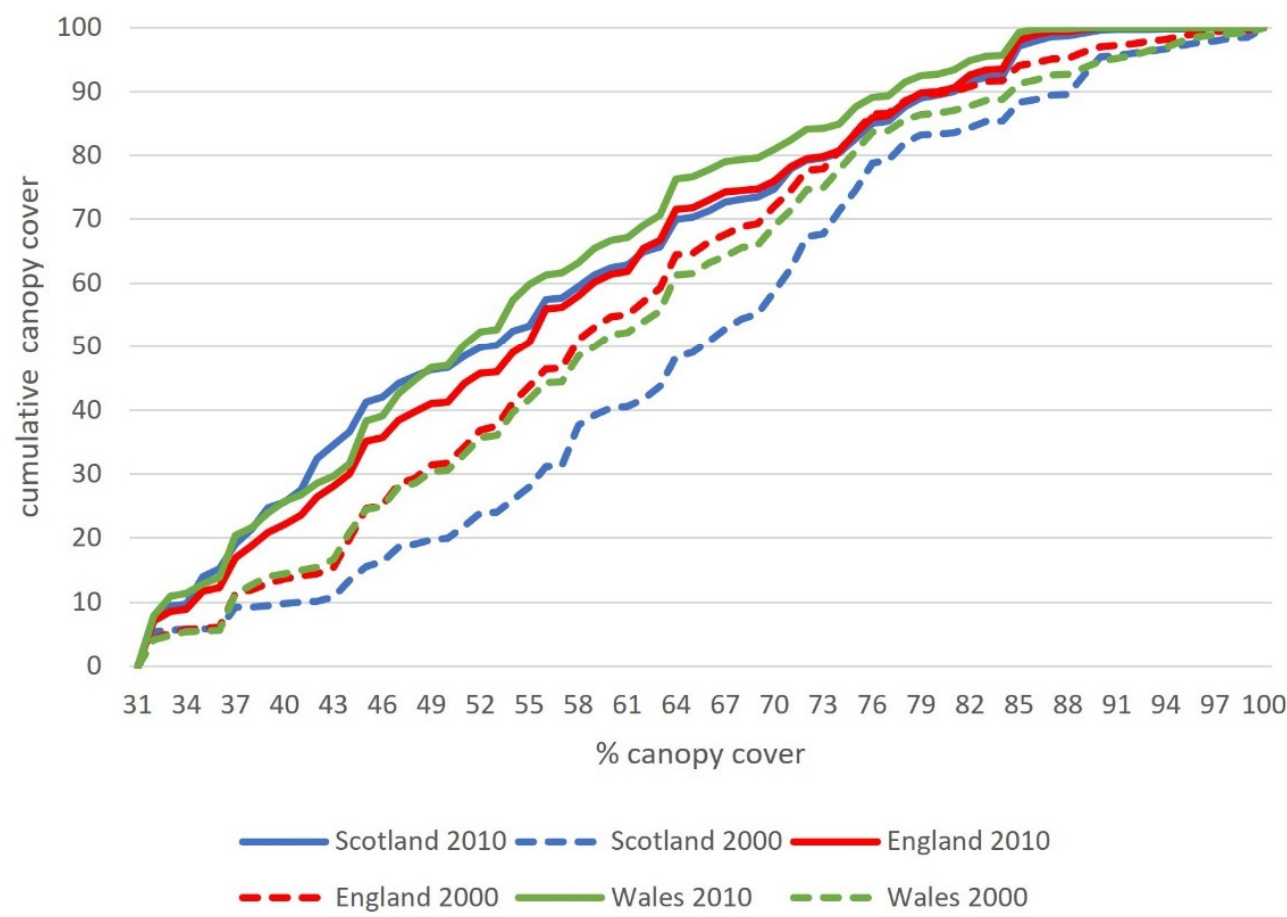

(b)

Figure 8. Areas of commission error between NFI and GLAD FC vs. percentage of canopy cover for (a) Heather habitat and (b) Improved grassland habitat.

\section{Discussion}

The high commission errors of both GLAD FC datasets demonstrate that they substantially overestimate forest land cover in Britain of up to 50\%. These errors are consistent across all nations. This is, to the best knowledge of the authors, the first time that such 
overestimation is observed for temperate environments. It also agrees with the findings reported on research that investigated the GLAD uncertainty in other environments such as the tropics $[11,14,26,27]$. This demonstrates that the use of GLAD data needs to be considered very carefully outside its originally intended purpose of deforestation detection. GLAD data are global in scope and in many locations might provide the only available land cover information. Nevertheless, as our results demonstrate, potential users should have a clear awareness of its limitations.

It is noteworthy that the results comparing datasets with no temporal difference (NFI 2010 vs. GLAD FC 2010) calculated higher commission errors than the datasets with a 10-year time gap. This increase in errors in the GLAD 2010 FC may have been caused by the use of Landsat 7 images affected by missing data associated with the scan line corrector failure.

Our analysis also demonstrated that the commission error is strongly related to specific habitat types. More than 50\% of the commission error was spatially distributed on various grassland habitats. However, when normalized to the national habitat proportions, the heather habitat (a heathland shrub with a maximum height of $<1 \mathrm{~m}$ ) is overrepresented in both the 2000 and 2010 data and therefore appears to be particularly prone to misclassification.

Both the heather and grassland habitats are predominantly represented as medium to low canopy cover forest, with the heather habitat having slightly lower canopy cover values than the grassland. This supports the hypothesis that misclassified habitats are more likely to be associated with areas of lower canopy cover. The observation of Tropek et al. (2014) of misclassification of similar low shrub vegetation does not mention any association with canopy cover, so it is not possible to make any comparisons [16]. A similar observation was made by [26], who investigated the suitability for Global Forest Watch data for quantifying harvested sites in a mountainous boreal forest catchment in south-central Norway. It was found that residual seed trees caused substantial errors of omission. It was also found that it was necessary to remove small isolated forest cover loss patches that had a high probability of representing commission errors.

The temporal difference between the CEH 2015 Land Cover data set and the commission errors introduce a potential for thematic inaccuracies, particularly between the 2000 GLAD FC map and the 2015 CEH Land Cover data, as habitat changes will inevitably have taken place over the 15-year time gap. However, these inaccuracies are significantly reduced in the heathland habitats as they have been protected by EU law since 1992 (https: / / www.eea.europa.eu/data-and-maps/data/natura-11, accessed on 10 July 2020) [33].

The potential overestimation of forest cover in areas with medium-density canopy cover explains the need to recalibrate the data in Gabon and Guyana, as mentioned in [14] and [11], where values of $70 \%$ and $94 \%$ thresholds needed to be used to calibrate the data with national reference sets. This suggests that areas that are dominated by high canopy cover (such as tropical rain forests) and sharp transitions to no forest areas can be recalibrated to produce a more accurate estimate of forest cover.

Attempts to recalibrate the GLAD data in the context of this study are more challenging because medium canopy values are represented by a mix of forest and no forest habitats. This leads to a reduction in commission error but an increased omission error and therefore does not increase the data's overall ability to predict forest cover.

It should be acknowledged that these commission errors (across multiple habitat types and a wide range of canopy covers) can have multiple causes that are not addressed by the habitat and canopy cover analysis. For example, terrain, aspect, altitude, proximity to areas of agreement, and positional errors associated with the analysis process are all possible additional causes as well as the choice of acquisition and processing parameters. Further work on the proportion of errors associated with these potential causes and their spatial occurrence would add to the better understanding of these errors and their likely occurrence in other environments across the world. 


\section{Conclusions}

The results of our analysis demonstrate that substantial care needs to be taken when using GLAD data for temperate climates such as the United Kingdom. This is because the accuracy assessment showed substantial commission errors. This highlights potential problems that might occur when GLAD datasets are employed for other purposes than its originally intended use, as was debated in the context of recent forest change models in Europe [5-8].

Misclassification was observed to more likely occur in habitats with low to medium canopy cover. This is likely to be due to the increased potential for overlapping spectral signatures between areas of genuine medium to low canopy forest cover and non-forest vegetation. Given the global scope of the GLAD dataset, incomplete training data might be a contributor to misclassifications in this context [27].

The strength of both the OS 2019 and the NFI datasets as good reference data not only lies in their high level of detail and accuracy being based on continually updated ground surveys and aerial photography but also on their definition of forest being based on land cover rather than land use. The use of this wall-to-wall ground-surveyed reference data has achieved a higher level of accuracy than using sampled data, and therefore, the utilization of ground-referenced NFIs to assess satellite-based datasets in other European countries with similar habitats and land parcel sizes is highly recommended.

Nevertheless, GLAD data can aid in the creation of local or regional forest datasets with the use of local reference data by adjusting the forest/no forest canopy cover switch to match the local data. However, this approach favours areas with a substantial proportion of high-canopy cover such as large undisturbed areas of temperate or tropical forest [11,12]. GLAD data appear to be less useful in regions with a high proportion of medium to low-density canopy cover. In such cases, it should only be used in conjunction and crosscalibration with good quality reference data.

The Glad FC data successfully flagged deforested areas within tree farmed areas in our case study before they were mapped by the NFI. This demonstrates the effectiveness of GLAD data in its intended use as a flag for forest loss. Therefore, it has the potential to improve the temporal accuracy of areas with well-established forest inventories as well as help in poorly mapped areas of the world.

Author Contributions: Conceptualization, Clare Price and Paul Elsner; methodology, Clare Price and Paul Elsner; validation, Clare Price; formal analysis, Clare Price; data curation, Clare Price; writing—original draft preparation, Clare Price and Paul Elsner; writing-review and editing, Clare Price and Paul Elsner; visualization, Clare Price; supervision, Paul Elsner. All authors have read and agreed to the published version of the manuscript.

Funding: This research received no external funding.

Data Availability Statement: Data used in the accuracy assessments and habitat analysis are based on open data sources detailed in Table 1. Additional data include EU-protected site polygons from https://www.eea.europa.eu/data-and-maps/data/natura-11, accessed on 10 July 2020 and the Global Forest Watch report used to quality check the downloaded Glad 2010 tree cover. Any other material that support the findings of this study are available from the corresponding author, Clare Price, upon reasonable request.

Acknowledgments: The authors gratefully acknowledge the open data provided by GLAD and Global Forest Watch, National Forestry Commission of the UK, Ordnance Survey, Centre for Ecology and Hydrology, European Space Agency and the European Environment Agency.

Conflicts of Interest: The authors declare no conflict of interest.

\section{References}

1. Popp, A.; Humpenöder, F.; Weindl, I.; Bodirsky, B.L.; Bonsch, M.; Lotze-Campen, H.; Müller, C.; Biewald, A.; Rolinski, S.; Stevanovic, M.; et al. Land-use protection for climate change mitigation. Nat. Clim. Chang. 2014, 4, 1095-1098. [CrossRef]

2. Canadell, J.G.; Raupach, M.R. Managing forests for climate change mitigation. Science 2008, 320, 1456-1457. [CrossRef] [PubMed] 
3. Carvalho, G.; Moutinho, P.; Nepstad, D.; Mattos, L.; Santilli, M. AN Amazon Perspective on the Forest-Climate Connection: Opportunity for Climate Mitigation, Conservation and Development? Environ. Dev. Sustain. 2004, 6, 163. [CrossRef]

4. Lindenmayer, D.B.; Franklin, J.F.; Fischer, J. General management principles and a checklist of strategies to guide forest biodiversity conservation. Biol. Conserv. 2006, 131, 433-445. [CrossRef]

5. Brunialti, G. Integrative approaches as an opportunity for the conservation of forest biodiversity. Int. J. Environ. Stud. 2014, 71, 226-227. [CrossRef]

6. $\quad$ Sodhi, N.S.; Koh, L.P.; Clements, R.; Wanger, T.C.; Hill, J.K.; Hamer, K.C.; Clough, Y.; Tscharntke, T.; Posa, M.R.C.; Lee, T.M. Conserving Southeast Asian forest biodiversity in human-modified landscapes. Biol. Conserv. 2010, 143, 2375-2384. [CrossRef]

7. Brockerhoff, E.G.; Barbaro, L.; Castagneyrol, B.; Forrester, D.I.; Gardiner, B.; González-Olabarria, J.R.; Lyver, P.O.; Meurisse, N.; Oxbrough, A.; Taki, H.; et al. Forest biodiversity, ecosystem functioning and the provision of ecosystem services. Biodivers. Conserv. 2017, 26, 3005-3035. [CrossRef]

8. Moomaw, W.R.; Law, B.E.; Goetz, S.J. Focus on the role of forests and soils in meeting climate change mitigation goals: Summary Environ. Res. Lett. 2020, 15, 045009. [CrossRef]

9. Noss, R.F. Assessing and monitoring forest biodiversity: A suggested framework and indicators. For. Ecol. Manag. 1999, 115, 135-146. [CrossRef]

10. Burivalova, Z.; Bauert, M.R.; Hassold, S.; Fatroandrianjafinonjasolomiovazo, N.T.; Koh, L.P. Relevance of Global Forest Change Data Set to Local Conservation: Case Study of Forest Degradation in Masoala National Park, Madagascar. Biotropica 2015, 47, 267-274. [CrossRef]

11. Galiatsatos, N.; Donoghue, D.N.M.; Watt, P.; Bholanath, P.; Pickering, J.; Hansen, M.C.; Mahmood, A.R.J. An assessment of global forest change datasets for national forest monitoring and reporting. Remote Sens. 2020, 12, 1790. [CrossRef]

12. Mitchell, A.L.; Rosenqvist, A.; Mora, B. Current remote sensing approaches to monitoring forest degradation in support of countries measurement, reporting and verification (MRV) systems for REDD+. Carbon Balance Manag. 2017, 12. [CrossRef] [PubMed]

13. Hansen, M.C.; Potapov, P.V.; Moore, R.; Hancher, M.; Turubanova, S.A.; Tyukavina, A.; Thau, D.; Stehman, S.V.; Goetz, S.J.; Loveland, T.R.; et al. High-resolution global maps of 21st-century forest cover change. Science 2013, 342, 850-853. [CrossRef] [PubMed]

14. Sannier, C.; McRoberts, R.E.; Fichet, L.V. Suitability of Global Forest Change data to report forest cover estimates at national level in Gabon. Remote Sens. Environ. 2016, 173, 326-338. [CrossRef]

15. Hansen, M.; Potapov, P.; Margono, B.; Stehman, S.; Turubanova, S.; Tyukavina, A. Response to comment on "High-resolution global maps of 21st-century forest cover change". Science 2014, 344, 2013-2014. [CrossRef]

16. Tropek, R.; Sedlaek, O.; Beck, J.; Keil, P.; Musilova, Z.; Imova, I.; Storch, D. Comment on "High-resolution global maps of 21st-century forest cover change". Science 2014, 344, 981. [CrossRef]

17. Abbas, S.; Wong, M.S.; Wu, J.; Shahzad, N.; Irteza, S.M. Approaches of satellite remote sensing for the assessment of above-ground biomass across tropical forests: Pan-tropical to national scales. Remote Sens. 2020, 12, 3351. [CrossRef]

18. Rerolle, F.; Dantzer, E.; Lover, A.; Marshall, J.M.; Hongvanthong, B.; Sturrock, H.J.W.; Bennett, A. Spatio-temporal associations between deforestation and malaria incidence in Lao Pdr. Elife 2021, 10, e56974. [CrossRef]

19. Shah, V.; Shah, A.; Joshi, V. Predicting the origins of next forest-based emerging infectious disease. Environ. Monit. Assess. 2018, 190, 337. [CrossRef]

20. Havašová, M.; Ferenčík, J.; Jakuš, R. Interactions between windthrow, bark beetles and forest management in the Tatra national parks. For. Ecol. Manag. 2017, 391, 349-361. [CrossRef]

21. Ceccherini, G.; Duveiller, G.; Grassi, G.; Lemoine, G.; Avitabile, V.; Pilli, R.; Cescatti, A. Abrupt increase in harvested forest area over Europe after 2015. Nature 2020, 583, 72-77. [CrossRef] [PubMed]

22. Palahí, M.; Valbuena, R.; Senf, C.; Acil, N.; Pugh, T.A.M.; Sadler, J.; Seidl, R.; Potapov, P.; Gardiner, B.; Hetemäki, L.; et al. Concerns about reported harvests in European forests. Nature 2021, 592, E15-E17. [CrossRef] [PubMed]

23. Ceccherini, G.; Duveiller, G.; Grassi, G.; Lemoine, G.; Avitabile, V.; Pilli, R.; Cescatti, A. Reply to Wernick, I.K. et al.; Palahí, M. et al. Nature 2021, 592, E18-E23. [CrossRef]

24. Wernick, I.K.; Ciais, P.; Fridman, J.; Högberg, P.; Korhonen, K.T.; Nordin, A.; Kauppi, P.E. Quantifying forest change in the European Union. Nature 2021, 592, E13-E14. [CrossRef] [PubMed]

25. Shimizu, K.; Ota, T.; Mizoue, N. Accuracy assessments of local and global forest change data to estimate annual disturbances in temperate forests. Remote Sens. 2020, 12, 2438. [CrossRef]

26. Yang, Z.; Dong, J.; Liu, J.; Zhai, J.; Kuang, W.; Zhao, G.; Shen, W.; Zhou, Y.; Qin, Y.; Xiao, X. Accuracy assessment and inter-comparison of eight medium resolution forest products on the loess plateau, China. ISPRS Int. J. Geo-Inf. 2017, 6, 152 [CrossRef]

27. Zhang, D.; Wang, H.; Wang, X.; Lü, Z. Accuracy assessment of the global forest watch tree cover 2000 in China. Int. J. Appl. Earth Obs. Geoinf. 2020, 87, 102033. [CrossRef]

28. Congalton, R.G. Thematic and Positional Accuracy Assess- ment of Digital Remotely Sensed Data. In Proceedings of the Seventh Annual Forest Inventory and Analysis Symposium, Washington, DC, USA, 3-6 October 2005; pp. 149-154.

29. Olofsson, P.; Foody, G.M.; Herold, M.; Stehman, S.V.; Woodcock, C.E.; Wulder, M.A. Good practices for estimating area and assessing accuracy of land change. Remote Sens. Environ. 2014, 148, 42-57. [CrossRef] 
30. Rowland, C.S.; Morton, R.D.; Carrasco, L.; McShane, G.; O'Neil, A.W.; Wood, C. Land Cover Map 2015 (Vector, GB); NERC Environmental Information: Data Centre, UK, 2017. [CrossRef]

31. FAO. The Forest Resources Assessment Programme Country Report UK of Great Britain and Northern Ireland; Food and Agriculture Organization: Rome, Italy, 2015.

32. Bibby, P. Land use change in Britain. Land Use Policy 2009, 26, S2. [CrossRef]

33. European Environment Agency Natura 2000 Data-The European Network of Protected Sites. Available online: http://natura2 000.eea.europa.eu/ (accessed on 10 July 2020). 